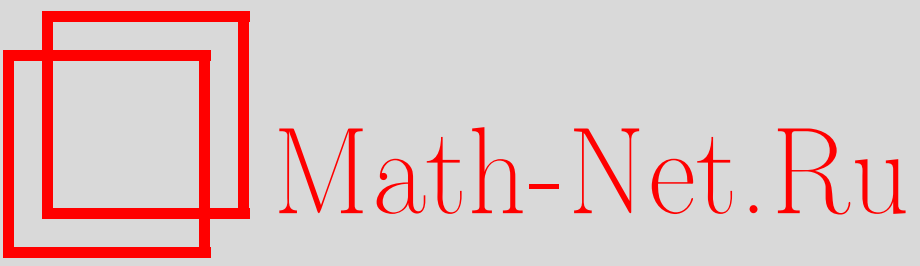

О. А. Логинов, А. Л. Савельев, Моделирование напряжённого-деформируемого состояния нижней челюсти при остеосинтезе накостными пластинами, Beстн. Сам. гос. техн. ун-та. Сер. Физ.-мат. науки, 2011, выпуск 4(), 169-172

DOI: https://doi.org/10.14498/vsgtu919

Использование Общероссийского математического портала Math-Net.Ru подразумевает, что вы прочитали и согласны с пользовательским соглашением http: //www. mathnet.ru/rus/agreement

Параметры загрузки:

IP : 18.207 .199 .55

26 апреля 2023 г., 06:20:10 


\title{
Биомеханика
}

УДК 517.958:57.089

\section{МОДЕЛИРОВАНИЕ НАПРЯЖЁННОГО-ДЕФОРМИРУЕМОГО СОСТОЯНИЯ НИЖНЕЙ ЧЕЛЮСТИ ПРИ ОСТЕОСИНТЕЗЕ НАКОСТНЫМИ ПЛАСТИНАМИ}

\author{
О. А. Логинов ${ }^{1}$ А. Л. Савелъев ${ }^{2}$ \\ 1 Самарский филиал ОАО «ОргЭнергоНефть», \\ 443013, г. Самара, ул. Чернореченская, 50. \\ 2 Самарский государственный медицинский университет, \\ 443099, г. Самара, ул. Чапаевская, 89. \\ E-mail: loa-oen@yandex.ru
}

Исследуется напряжённо-дебормированное состояние нижней челюсти при остеосинтезе накостными пластинами. Для этого используется математическая модель, построенная с помощъю метода конечных элементов. Полученные результаты позволяют определить оптимальные размеры и типы накостных пластин и способъ их крепления.

Ключевые слова: перелом, нижняя челюстъ, хирургическое лечение, математическое моделирование, конечно-элементная модель.

Для лечения переломов нижней челюсти в настоящее время широко используют метод хирургической фиксации отломков [1]. Накостные пластины среди множества других способов и устройств обладают существенным преимуществом, так как обеспечивают надежную и стабильную фиксацию отломком даже в тех случаях, когда другие способы не дают полноценного лечебного эффекта. Следует при этом отметить, что в настоящее время при остеосинтезе нижней челюсти далеко не в полной мере определены оптимальные размеры и типы накостных пластин и способы их крепления. Трудность решения подобных задач заключается в необходимости учитывать как сложную реологию материалов, так и значительный разброс геометрических размеров тел и действующих нагрузок. Целью настоящей работы является построение математической модели для оценки напряженно-деформированного состояния нижней челюсти при остеосинтезе накостными пластинами, реализованной в пакете конечно-элементного анализа ANSYS [2].

На первом шаге была построена геометрическая модель нижней челюсти. Ввиду значительной вариации геометрических размеров и неинформативности «усредненной» модели был выбран вариант построения модели, по возможности близкий по своим параметрам к вполне определенному пациенту.

Построение модели велось по сечениям, полученным при проведении компьютерной томографии (KT). Геометрические размеры сечения челюсти, полученные при $\mathrm{KT}$, с незначительными поправками (идеализацией) импортировались в пакет ANSYS и на них выстраивалась модель челюсти. Для моделирования накостных пластин было выбрано несколько вариантов накостных пластин, как широко используемых в клинической практике, так и только прошедших апробацию. Вид использованных моделей нижней челюсти представлен на рис. 1.

Олег Александрович Логинов (к.ф.-м.н., доц.), главный специалист, отд. экспертизы технических устройств. Александр Леонидович Савельев, ассистент, каф. челюстно-лицевой хирургии и стоматологии. 

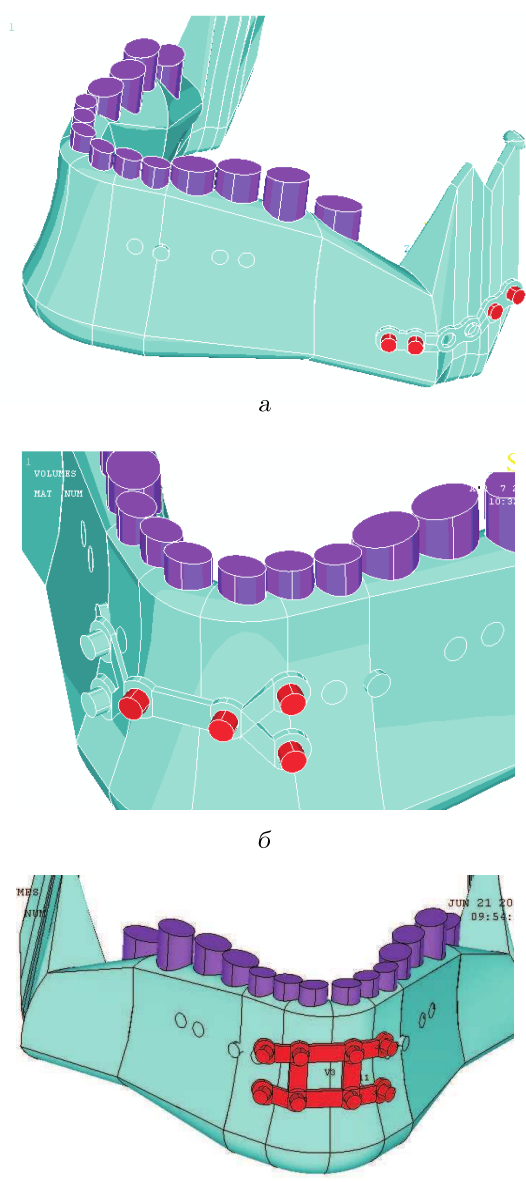

Рис. 1. Вид твёрдотельной модели нижней челюсти: а) с дугообразной накостной пластиной; б) с х-образной накостной пластиной; в) с накостными пластинами

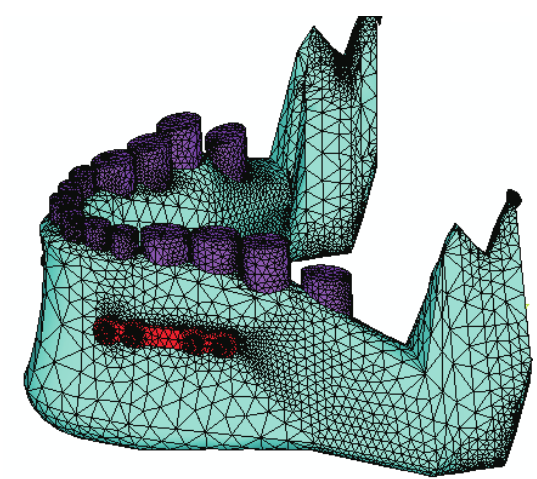

Рис. 2. Вид конечно-элементной модели нижней челюсти с накостной пластиной. В зоне пластины имеется сгущение сетки конечных элементов
На втором шаге было проведено разбиение модели на конечные элементы. Исходя из возможного вклада погрешности модели в итоговые результаты и имеющихся вычислительных ресурсов, производилась некоторая идеализация исходной геометрии. Было создано несколько моделей с различной степенью детализации, из которых была выбрана оптимальная, состоящая из 50000 конечных элементов, что позволяет достаточно оперативно проводить конечно-элементный расчёт (в пределах 1-4 часов) и в то же время обеспечивает приемлемую точность. Результат конечно-элементного моделирования нижней челюсти представлен на рис. 2.

На третьем шаге задавались прочностные параметры тканей нижней челюсти и условия её нагружения. При проведении расчётов поведение материала принималось линейно упругим: величина модуля Юнга для костной ткани принималась равной 13,7 ГПа, а коэффициент Пуассона - 0,3.

После построения математической модели задавались граничные условия и нагрузки. Силы, развиваемые мышцами, прикреплёнными к нижней челюсти, моделировались распределёнными силами (давлением), приложенными к области, где происходит крепление мышщ (в районе расположения 6-8 зубов). В области суставного отростка моделировалось шарнирное закрепление, после чего был проведён расчёт его напряжённо-деформируемого состояния.

В результате расчёта получено распределение значений напряжений (на рис. 3 приведён вид одного из рассматриваемых случаев нагружения для распределённых усилий, равнодействующая которых составляет $200 \mathrm{H})$.

Сама по себе максимальная величина напряжений не может служить единственным критерием, объясняющим весь процесс выздоровления, поскольку имеются и другие (возможно, не менее важные) величины, определяющие ход биологических процессов, например, размер зоны, где напряжения превышают некоторую пороговую величину. Важно отметить, что при моделировании твёрдых тел одно из важнейших исходных положений - это модель сплошной среды, т. е. физико-механические свойства тела на микроуровне полагаются неизменными внутри описываемой области. Однако для рассматриваемых тел (как и для любых 
тел биологического происхождения) указанное предположение не является справедливым при рассмотрении областей, имеющих линейные размеры, которые не превышают размера структурного элемента костной ткани, что, в свою очередь, не позволяет распространить математическое моделирование с использованием аппарата теории упругости однородных сред внутрь столь малого объёма. Указанное ограничение следует учитывать при конечно-элементном моделировании нижней челюсти на этапе оценки оптимального размера конечного элемента: простое уменьшение линейного размера с целью повышения точности получаемого решения, широко используемое

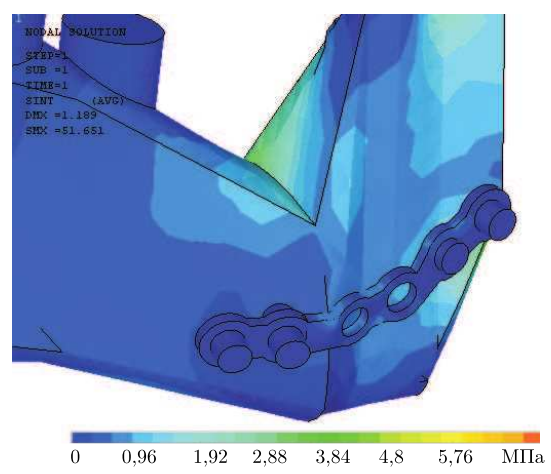

Рис. 3. Распределение величины интенсивности напряжений в нижней челюсти в других областях механики деформируемого твёрдого тела, может привести к совершенно неадекватным (сильно завышенным) значениям напряжений при моделировании биологических тел. Учитывая размер структурного элемента костной ткани, можно рекомендовать при геометрическом разбиении тела не допускать уменьшения линейного размера конечного элемента менее 0,5 мм, а в случае наличия в полученном решении зон, где напряжения превышают указанный уровень, но их размер не превышает 0,2-0,3 мм, при последующем анализе решения в «целом» не принимать их во внимание.

Следует отметить, что в литературе приводятся (экспериментально полученные на неживых тканях) значения напряжений, при которых происходит разрушение (разрыв) костных тканей, однако эти значения могут служить лишь некоторым ориентиром для определения напряжений, при которых начинает происходить биологическая деградация живых костных тканей.

Фактором, который усложняет модель поведения костной ткани, является наличие привносимой зоны разрушения костной ткани - зоны, в которой производится установка шурупов для закрепления накостных пластин. Именно в зоне, непосредственно примыкающей к отверстию, находится зона концентрации напряжений. В силу особенности математического моделирования геометрических характеристик системы крепежа накостных пластин именно в этих зонах возможно получение сильно завышенных значений величин напряжений в костной ткани.

Среди многих величин (максимальное значение напряжений; допускаемое напряжение; размер зоны, где напряжения превышают допускаемое значение, «степень травматичности пластины» - и это далеко не полный перечень), по которым можно определить степень оптимальности используемой пластины, в настоящей работе использован критерий максимального напряжения в костной ткани.

Анализ распределения величины напряжений в конечно-элементной модели для различных видов нагружений позволяет определить оптимальную схему приложения накостных пластин.

В ходе решения поставленной задачи рассмотрены конечно-элементные модели, описывающие поведение нижней челюсти с накостными пластинами трёх видов: прямая пластина, дугообразная пластина и х-образная пластина с расположением переломов в центре челюсти, в районе 4, 5 зубов и в районе 6-8 зубов.

Анализ результатов полученного решения для 9 случаев нагружения показал, что согласно критерию максимального напряжения некоторое преимущество имеется у х-образных пластин, причём для всех трёх случаев расположения перелома (см. таблицу). При этом следует отметить, что указанное преимущество относится лишь к критерию максимального напряжения, и рекомендовать указанный вид пластин для преимущественного использования следует только после более полного (с учётом других критериев) исследования. 


\begin{tabular}{|c|c|c|c|c|c|c|}
\hline \multirow{2}{*}{$\begin{array}{c}\text { Местоположение пере- } \\
\text { лома (величина преде- } \\
\text { ла прочности, МПа) }\end{array}$} & \multicolumn{3}{|c|}{$\begin{array}{c}\text { Абсолютные макси- } \\
\text { мальные значения } \\
\text { напряжений, МПа }\end{array}$} & \multicolumn{3}{|c|}{$\begin{array}{c}\text { Относительные значе- } \\
\text { ния напряжений (доля } \\
\text { от величины допускае- } \\
\text { мого напряжения) }\end{array}$} \\
\hline & \begin{tabular}{|} 
прямая \\
пластина
\end{tabular} & $\begin{array}{c}\text { дугобразная } \\
\text { пластина }\end{array}$ & $\begin{array}{c}\text { x-образная } \\
\text { пластина }\end{array}$ & \begin{tabular}{|} 
прямая \\
пластина
\end{tabular} & $\begin{array}{c}\text { дугобразная } \\
\text { пластина }\end{array}$ & $\begin{array}{c}\text { x-образная } \\
\text { пластина }\end{array}$ \\
\hline Центр $1,2,3 \quad(25,2)$ & 5,1 & 5,3 & 4,2 & 0,20 & 0,21 & 0,17 \\
\hline Район 4,5 зубов $(24,8)$ & 5,6 & 5,6 & 4,4 & 0,23 & 0,23 & 0,18 \\
\hline Район $6-8$ зубов $(35,0)$ & 5,8 & 6,1 & 5,2 & 0,16 & 0,17 & 0,15 \\
\hline
\end{tabular}

\section{БИБЛИОГРАФИЧЕСКИЙ СПИСОК}

1. Бернадский Ю. И. Травматология и восстановительная хирургия черепно-челюстно-лицевой области. М.: Медицинская литература, 1999. 456 с. [Vernadskiy Yu. M. Trauma and reconstructive surgery of maxillofacial region. Moscow: Medicinskaya Literatura, 1999. 456 pp.]

2. Каплун А.Б., Морозов Е.М., Олферъева М.A. ANSYS в руках инженера. Практическое руководство. М.: Едиториал УРСС, 2003. 272 c. [Kaplun A.B., Morozov E. M., Olfer'eva M. A. ANSYS in the hands of an engineer. A Practical Guide. Moscow: Editorial URSS, 2003. 272 pp.]

MSC: 74L15

\section{MODELLING OF STRESS-STRAIN STATE IN MANDIBLE WITH OSTEOSYNTHESIS BY BONE PLATE}

\section{O.A. Loginov ${ }^{1}$, A.L. Savelyev ${ }^{2}$}

1 JSC «OrgEnergoPetroleum», Samara Branch,

50, Chernorechenskaya str., Samara, Russia, 443013.

2 Samara State Medical University,

89, Chapaevskaya str., Samara, Russia, 443099.

E-mail: loa-oen@yandex.ru

A finite element model of mandible by bone plate is proposed. It is shown that presented model can be used for the determination of optimal parameters of plate.

Key words: fracture, mandible, surgical treatment, mathematic modeling, finite element model.

Original article submitted 31/I/2011; revision submitted 16/VIII/2011.

Oleg A. Loginov (Ph. D. (Phys. \& Math.)), Chief specialist, Dept. of Technical Devices Expertise. Alexandr L. Saveliev, Assistent, Dept. of Maxillofacial Surgery and Dentistry. 